\title{
AC 2007-2655: OVERCOMING THE ETHICAL DANGERS OF ACADEMIC FAIR USE IN THE HIGH TECHNOLOGY CLASSROOM
}

\section{Edward Sobiesk, United States Military Academy}

Edward Sobiesk has a Ph.D. in Computer and Information Sciences from the University of

Minnesota. He is currently an Assistant Professor and Course Director for the course IT305-Theory and Practice of Military IT Systems in the Department of Electrical Engineering and Computer Science at the United States Military Academy. He can be reached at edward.sobiesk@us.army.mil.

\section{William Suchan, United States Military Academy}

Will Suchan has a Ph.D. in Computer Science from Arizona State University. He is the Information Technology Core Program Director in the Department of Electrical Engineering and Computer Science at the United States Military Academy. He can be reached at william.suchan@usma.edu.

\section{Roland Trope, United States Military Academy}

Roland L. Trope is a partner in the New York City office of Trope and Schramm LLP and an adjunct professor in the Department of Law at the US Military Academy. He is an Associate Editor for IEEE Security \& Privacy. Contact him at roland.trope@verizon.net. 


\title{
Overcoming the Ethical Dangers of Academic Fair Use in the High Technology Classroom
}

\begin{abstract}
The primary factor causing the world to shrink in the 21 st century is the Internet. While webenabled services enhance information sharing and facilitate collaboration, the proliferation of the Internet has also led to an erosion of respect for intellectual property. A key contributor to this erosion is the concept of Academic Fair Use. On the surface, Academic Fair Use would appear to be a means of protecting intellectual property. In reality, Fair Use policies can lead to an increase in less-than-ethical practices that are bred in academia and then transfer to the workplace. In this paper, we identify the problems associated with employing Academic Fair Use, and then share techniques that we use to help our students internalize ethical practices.
\end{abstract}

\section{Introduction}

In a technology-enhanced classroom, professors routinely make use of various multimedia devices that display images, movie clips, animations, and other types of media readily found on the Internet. Professors usually display these types of media without guilt, believing that they are within the guidelines of Academic Fair Use. Students likewise use these same types of media snippets in their design projects and briefings, also enjoying the false security blanket of Academic Fair Use. Quite often, they are both wrong. Right or wrong, though, the invocation of Academic Fair Use guidelines is a crutch that is rarely scrutinized. It can lead to inadvertent copyright infringement, but more importantly, it severely impacts the proper ethical development of students.

Professors treat Academic Fair Use as if it is a right granted to them based on their professional position, instead of what it actually is -- a defense for copyright infringement. The strength of the defense offered by Academic Fair Use is not our major issue. Instead, the issue is the lesson that professors are imparting to their students. The behavior that professors model for and encourage in their students by using an Academic Fair Use defense when employing copyrighted material leaves students with a stunted ethical perspective and ingrained bad habits. Students come to believe that "borrowing" the intellectual property of others, especially in a digital format, is easily justified, since the professors they trust and respect do it all the time, and allow them to do it as well. Even when the professors are well within the guidelines of Academic Fair Use, the process is usually transparent to the students. From the student point of view, Academic Fair Use looks and feels like "Free" Use. Once these students graduate, it is easy for them to rationalize their misperceptions of intellectual property and to continue operating in ethical grey areas with respect to copyright.

With the 750 students per year that take our course here at the United States Military Academy, we encourage them to abandon the notion of Academic Fair Use, and ask that they show the same respect for intellectual property when they are students as they will be required to show once they graduate. Rather than allowing our students to avoid intellectual property issues, we force them to confront the issues head on. One of our most significant outcomes is that our

The views expressed in this paper are those of the authors and do not reflect the official policy or position of the United States Military Academy, the Department of the Army, the Department of Defense or the United States Government. 
students not only understand that most of the material they find on the Internet is protected by copyright law, but they also experience the process of ensuring they have permission before using copyrighted material. All this takes place not in a seminar class on ethics, but in mainstream Information Technology classrooms.

The central themes of this paper have evolved from a long term collaborative effort. Two of the authors are computer scientists who are faculty members in the Academy's Department of Electrical Engineering and Computer Science. They are directly responsible for the content and execution of the Information Technology course described throughout this paper. Our third author is a lawyer who is an adjunct faculty member with the Academy's Department of Law. He serves as both guest lecturer and advisor for our Information Technology course. The main concepts of this work were developed through the synergy of this interdisciplinary team, and we view our collaborative effort as a model for the direction that education should move towards in the future.

\section{Background}

United States (U.S.) copyright protections and privileges are generally automatically granted to any work that is expressed in a fixed, tangible medium. Since any digital representation is both fixed and tangible, this means that for almost everything found on the Internet (with a few exceptions, such as public domain and U.S. government works), there is an owner who holds the copyright. A U.S. copyright owner enjoys several exclusive rights, including the right to copy or reproduce, the right to prepare "derivative" works, and the right to control distribution or transfer of the work. This places Internet users in a unique and complex situation -- almost anything downloaded or copied from the Internet without permission makes the user susceptible to violating copyright law.

Violation of copyright law is not a foreign concept in the $21^{\text {st }}$ Century. Many recent legal cases in the headlines have brought online piracy into the consciousness of high school and college students. According to the Recording Industry Association of America, online piracy is defined as "...the unauthorized uploading of a copyrighted sound recording and making it available to the public, or downloading a sound recording from an Internet site...." While we certainly want our students to be knowledgeable about issues such as online piracy, its well-publicized prevalence makes it better understood and therefore not as great a danger for "inadvertent" violations. We focus instead on common situations in which copyright infringement not only goes unnoticed, but is often subtly encouraged.

One of the problems with Fair Use, and especially with Academic Fair Use, is that the absolute boundaries are constantly being redrawn by the courts. The Conference on Fair Use ${ }^{2}$ set the stage for the current state of Fair Use in general, but the guidelines have been often contested, and every new media type and court ruling necessitates that the guidelines be revisited. To make the current rules understandable for faculty members, our college legal office published an information paper $^{3}$ as a guide on Academic Fair Use. The 11 page document explains in excruciating detail that "X\% or Y seconds of media type A may be used (whichever is less), but in no case for more than Z semesters." Needless to say, the legalese is of little use for most faculty members, many of whom are not even aware that this document exists.

The views expressed in this paper are those of the authors and do not reflect the official policy or position of the United States Military Academy, the Department of the Army, the Department of Defense or the United States Government. 
Application of Academic Fair Use by professors falls into three general categories. The first category consists of those situations when a professor chooses to ignore the principles of Academic Fair Use, infringing on copyrights with impunity. While this category of abuse certainly exists, we will not address it here. The second category includes those situations when a professor tries to adhere to the tenets of Fair Use, but, either through misinterpretation of the requirements or through poor judgment, ends up exceeding Fair Use guidelines, which is easy to do since court interpretations of this issue continue to evolve. The professors in each of these two categories demonstrate for their students infringement of copyright law. The fact that in one of the situations the professors are at least trying to do the right thing is not an excuse for infringement in the eyes of the law.

The remaining category is the main focus of our efforts. This category consists of the group of professors who use copyrighted material in the classroom only after ensuring that they are well within the acceptable bounds of Academic Fair Use. The paradoxical truth here is that even these professors are demonstrating for their students infringement of copyright law, albeit with an acceptable defense already in place. This defense, though, is usually unknown to the students, as is the fact that use of the defense means that infringement has already occurred. In subsequent sections, this paper addresses why reliance on the protections offered by Academic Fair Use in the high technology classroom may be doing more harm than good.

\section{Problems associated with employing Academic Fair Use}

In order to consider whether Academic Fair Use should be minimized in an educational environment, it is important to first agree upon the desired outcomes of the educational process. From a behavioral perspective, we want to permanently affect students' minds and to change the way they view the world. If students truly understand the protections afforded by copyright laws, they are more likely to view all copyrighted material in an appropriate way. If, however, they repeatedly see the apparent abuse of copyrighted material in an unrestricted manner, they tend to gravitate towards developing bad habits.

It would be hard enough to accomplish our intended mission if the students came to us knowing nothing about copyright. It is even harder, though, because they usually come to us with a mental model ${ }^{4}$ of digital copyright protections that is badly skewed. Current undergraduates have grown up in a digital age, and their mental model of digital property is well formed by the time they get to college. They believe that, if they can access something, they have a right to it. Whether their intended target is a song, a video, or a photograph, an Internet search engine makes every form of digital media readily available, and typically for free. Simply telling students that they don't have the right to take and use whatever they can find clashes with their mental model. On the other hand, when students are in class and they see their professors using media downloaded from the Internet, this reinforces their mental model. In reality, the professor may be using something in a way that falls within the bounds of Academic Fair Use, but the student only sees the fact that copyrighted material is being used.

In a technical discipline, we often have students build physical artifacts such as a circuit, a model, or a system. The reason for constructing these things, however, is not to train the

The views expressed in this paper are those of the authors and do not reflect the official policy or position of the United States Military Academy, the Department of the Army, the Department of Defense or the United States Government. 
students to work with their hands. Hands-on experiences are used to internalize certain concepts in the minds of the students. Likewise, when students use copyrighted material in a manner that is not correct, or see their professors doing the same, it is those behaviors that are ingrained in the minds of the students. This problem of ingraining incorrect behaviors is present even when the professor and the students are complying with the Academic Fair Use doctrine. The reason is that the students don't see what the professor does behind the scenes to ensure legal use of copyrighted material, and student adherence to Academic Fair Use is often more by chance than by intent. The students only see the end result -- that copyrighted material is used, seemingly without constraint. Once the student graduates and is no longer operating within the cocoon of Academic Fair Use, using those ingrained behaviors can get the individual in trouble.

In his one-day course, "Presenting Data and Information," Dr. Edward Tufte makes a powerful argument for using source material in slides used to accompany presentations. ${ }^{5}$ He also emphasizes that, in order to maximize credibility, the reference to the source should be annotated directly in the presentation. While this is a practice that is very effective in conveying the message of the source data, it also promotes a prevalent misperception - that the use of the original source material is allowable as long as an attribution statement is included. In his accompanying book, Visual Explanations: Images and Quantities, Evidence and Narrative, ${ }^{6}$ Dr. Tufte follows his own advice and attributes sources as they are used throughout the text. In the endnotes, he extensively documents his permission to use all of the copyrighted material. He clearly goes to the extreme to prevent abusing the copyright privileges of others. Sadly, unless the reader explicitly searches for this page at the end of the book, that message is not conveyed.

In working with our own instructors, we encourage them to follow Dr. Tufte's guidance by attributing presentation sources in the immediate proximity of the source material.

Unfortunately, the result is even worse than the book example above. The problem is that verbal presentations typically do not have endnotes. The attribution statements contained in accompanying slides often say something along the lines of "This graph was found at www.xyz.com." From the student perspective, they get used to seeing copyrighted material accompanied by an attribution statement, with no mention of permission. The difference between attribution and permission becomes murky. The incorrect subliminal message that comes through is this - as long as you attribute the source of the material, it is okay to use.

\section{Techniques we use to help our students build a good ethical framework}

We use three major techniques to help our students build a strong ethical foundation in the domain of intellectual property rights in cyberspace that will serve them throughout their lives.

\section{$\underline{\text { Instructor example }}$}

We are convinced that leadership by example is one of the most powerful tools an instructor possesses to permanently impact students (which is what we put forth as the goal of education). Professors can demonstrate respect for intellectual property in two ways. First, they can avoid using copyrighted material in the classroom even when it might be allowable under Academic Fair Use. Second, professors can explicitly and demonstrably seek permission to use the

The views expressed in this paper are those of the authors and do not reflect the official policy or position of the United States Military Academy, the Department of the Army, the Department of Defense or the United States Government. 
copyrighted material of others. By explicitly doing this, the professor teaches the students to do likewise.

\section{Confront the issue head on}

Our second technique to help our students internalize a good ethical framework is to have them confront the issue head on. Our goal is to create an environment of educated self-confidence, not one of fear and avoidance of Internet resources. We believe that a key aspect of Information Technology is using and expanding on the work of others. ${ }^{7}$ The first project in our course requires three-person groups to build a team web portal. The portal is used as the submission mechanism for the remaining course projects, so it continues to be expanded and refined throughout the semester. Students also construct personal web sites that are linked to their portal. The assignment instructions require our students to employ multimedia content for both the individual and team portions of their submission. We teach our students how to do this safely by:

- encouraging them to seek permission from the copyright owner if they find multimedia content or a design they want to employ,

- showing them open source and public domain material that is permissible to use with minimal action on their parts, and

- encouraging them to create works themselves (on a web page, for example, a photograph taken by the student is often more creative and more appropriate than one downloaded from the Internet).

A key aspect of our educational process is teaching students how to succeed within the ethical framework that they are developing. An excellent example of this concept is the manner in which we teach our students how to look for potential web designs to use in their web portal project. In order to highlight this model for our students, we contrast the Zen Garden web site ${ }^{8}$ with the Open Source Web Design (OSWD) web site. ${ }^{9}$ Both have numerous interesting designs and graphics. With Zen Garden, though, the site clearly states that a viewer may not use any of the graphics without contacting the author and obtaining permission. The viewer is also discouraged from using any of the available cascading style sheet designs without explicit permission. Besides this, most of the designs are focused completely on the Zen Garden content and could not be easily changed to suit a user's content. With OSWD, on the other hand, the designs each carry their own open source license agreement which describes how one may legally use the creator's design. This often entails simply giving credit to the original designer at the bottom of the page. The OSWD designs are meant to be modified with whatever content the user wishes to place in them, and often with a few personalized pictures and text, a student can have a very professional site completed in a reasonable period of time.

Students who explicitly seek permission to use copyrighted material from a copyright holder, and then have that permission granted, have consistently displayed a great deal of enthusiasm. The educational impact is tremendous. Students learn that the cost involved is often negligible, and they feel empowered to do the right thing. In those rare instances when either a professor or student asks for permission, and that permission is denied, there is an even greater learning

The views expressed in this paper are those of the authors and do not reflect the official policy or position of the United States Military Academy, the Department of the Army, the Department of Defense or the United States Government. 
opportunity. It shows that the copyright system works, and that copyright holders truly have power over their creation.

\section{$\underline{\text { Repetition }}$}

Our final technique for constructing good ethical frameworks is to carefully time and repeat the message throughout the semester. Computing ethics in general is one of the semester-long threads that we come back to over and over again in our course. Many times, small excursions into ethics are student driven, because as they internalize the topic they start to see pertinent articles in the news, and they feel compelled to share them in class. When the students start driving these discussions, we know we are making an impact.

Around the time that the students begin to work on their web portal project, a podcast about intellectual property is provided as a listening assignment. The podcast was created by our lawyer colleague, but it is done in a way that cuts through the legalese so that it is understandable to the students. It gives several practical examples about proper use of copyrighted material that the students can use on their projects. In conjunction with the podcast, the students must complete a group exercise that addresses digital intellectual property. They look at a "completed" project and must identify how to properly handle different types of downloaded media. This leads to additional classroom discussion, which sets them up for success on their own projects. Finally, our lawyer colleague gives a guest lecture on intellectual property rights in cyberspace. This is done in groups small enough that individual questions can create a dialog, which makes it personal for the students. By proper timing and repetition of the message, we ensure that the students are both well informed and are practicing good habits as they construct their projects. The combined results of each of these techniques is that our students are able to build, or rebuild, an appropriate mental model with regards to intellectual property.

\section{Assessment}

One of the great challenges in education is how to assess whether you are succeeding. In this case, even determining what constitutes success can be difficult. For the domain of intellectual property rights in cyberspace, we define success as 1) our students understand the fundamentals of U.S. copyright law as it applies to the Internet, 2) our students have internalized an ethical framework (a mental model) that results in them respecting digital intellectual property and appropriately acting on that respect, and 3) our students understand the conceptual difference between Academic Fair Use, as it applies to them in an educational environment, and the Fair Use provisions that will apply to them after graduation.

Assessing these outcomes in a uniform manner is not possible. The first part of the success metric is relatively easy to assess. Short, scenario-based essay questions on this topic are easy to create, and we always include at least one of these questions on the midterm and/or final exam. This provides us with feedback on how well our students understand the mechanics of copyright law as it applies to the Internet.

The second measure of success is reflected in student project submissions. This measure is easier to assess anecdotally as opposed to methodically. We try very hard to get students to

The views expressed in this paper are those of the authors and do not reflect the official policy or position of the United States Military Academy, the Department of the Army, the Department of Defense or the United States Government. 
complete their projects without invoking an Academic Fair Use defense. Anecdotal evidence indicates that we are succeeding with at least a portion of the students. We have numerous success stories each semester where students enthusiastically relate to their instructor how they obtained permission to use something they needed, or how they created their own artifact instead of downloading something that was otherwise readily available. These are the types of results we never saw before we started emphasizing having permission and/or creating original content.

The last success measure will not be fully assessable for at least a few more years. We want to impact our students so that they possess a strong conceptual and ethical foundation, both at the time of their graduation and throughout the rest of their lives. We want our students to be making the right decisions 5-10 years from now based on their experience in our course. For these outcomes, we have no data as of yet. For now, we will continue to hone our assessment of what takes place during a student's time in our course. Part of our future work will be to seek methods of assessing our impact 5-10 years down the road. We are fortunate that we have multiple feedback mechanisms available to readily reach our graduates well into the future.

\section{Conclusion}

Pedagogically, respect and treatment of intellectual property is a concept that requires the same educational goals and methods as other topics. We submit that Academic Fair Use is hampering this end. Even when employed correctly, Academic Fair Use negatively impacts a student's mental model of intellectual property. Through teacher example, confronting the issue head on, and repeating the message throughout the course, we believe we are having a positive impact on our students' education in the complex and critical domain of intellectual property rights in cyberspace.

\section{References}

1. Recording Industry Association of America, http://www.riaa.com/issues/piracy/default.asp, 2006.

2. Lehman, B.A., et al., "The Conference On Fair Use : Final Report To The Commissioner

On The Conclusion Of The Conference On Fair Use,"

http://www.uspto.gov/web/offices/dcom/olia/confu/confurep.pdf, Nov 1998.

3. United States Military Academy, Information Paper: Fair Use, 24 June 2003.

4. Norman, D.A., The Design of Everyday Things, Doubleday, 1988, p. 17.

5. Tufte, E.R., "Presenting Data and Information," Seminar, New York, NY, 28 Sep, 2005.

6. Tufte, E.R., Visual Explanations: Images and Quantities, Evidence and Narrative, Graphics Press, Cheshire, Conn, 1997.

7. Sobiesk, E. J. and Suchan, W. K. "Starting in the Middle: Design and Implementation in the Information Age," Proceedings of the American Society for Engineering Education New England Section Conference, Worcester, MA, March, 2006.

8. “css Zen Garden: The Beauty in CSS Design,” http://www.csszengarden.com, 2007.

9. "Open Source Web Design," http://www.oswd.org, 2007. 